\title{
Supracricoid Laryngectomy: The Function of the Remaining Arytenoid in Voice and Swallowing
}

\author{
Elaine Cristina Pires Buzaneli ${ }^{1}$ Marcia Simões Zenari ${ }^{2}$ Marco Aurélio Vamondes Kulcsar ${ }^{3}$ \\ Rogerio A. Dedivitis ${ }^{3}$ Cláudio Roberto Cernea ${ }^{3}$ Kátia Nemr $^{1}$
}

\footnotetext{
${ }^{1}$ Departamento de Fisioterapia, Fonoaudiologia e Terapia Ocupacional, Faculdade de Medicina, Universidade de São Paulo, São Paulo, SP, Brazil

2 Department of Reabilitation, Instituto do Câncer, Hospital das Clínicas, Faculdade de Medicina, Universidade de São Paulo, São Paulo, SP, Brazil

3 Department of Head and Neck Surgery, Instituto do Câncer, Hospital das Clínicas, Faculdade de Medicina, Universidade de São Paulo, São Paulo, SP, Brazil
}

Int Arch Otorhinolaryngol 2018;22:303-312.

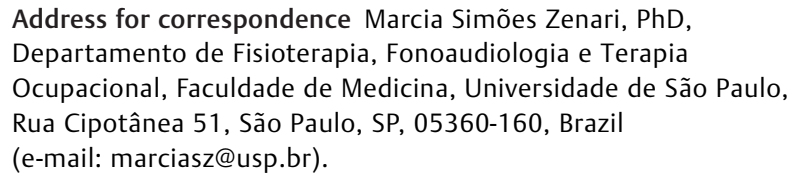

Address for correspondence Marcia Simões Zenari, PhD, Departamento de Fisioterapia, Fonoaudiologia e Terapia Ocupacional, Faculdade de Medicina, Universidade de São Paulo, Rua Cipotânea 51, São Paulo, SP, 05360-160, Brazil (e-mail: marciasz@usp.br).

\begin{abstract}
Keywords

- head and neck neoplasms

- laryngectomy

- voice

- deglutition

- speech therapy

Introduction Supracricoid laryngectomy still has selected indications; there are few studies in the literature, and the case series are limited, a fact that stimulates the development of new studies to further elucidate the structural and functional aspects of the procedure.

Objective To assess voice and deglutition parameters according to the number of preserved arytenoids.

Methods Eleven patients who underwent subtotal laryngectomy with cricohyoidoepiglottopexy were evaluated by laryngeal nasofibroscopy, videofluoroscopy, and auditory-perceptual, acoustic, and voice pleasantness analyses, after resuming oral feeding.

Results Functional abnormalities were detected in two out of the three patients who underwent arytenoidectomy, and in six patients from the remainder of the sample. Almost half of the sample presented silent laryngeal penetration and/or vallecular/ hypopharyngeal stasis on the videofluoroscopy. The mean voice analysis scores indicated moderate vocal deviation, roughness and breathiness; severe strain and loudness deviation; shorter maximum phonation time; the presence of noise; and high third and fourth formant values. The voices were rated as unpleasant. There was no difference in the number and functionality of the remaining arytenoids as prognostic factors for deglutition; however, in the qualitative analysis, favorable voice and deglutition outcomes were more common among patients who did not undergo arytenoidectomy and had normal functional conditions.

Conclusion The number and functionality of the preserved arytenoids were not found to be prognostic factors for favorable deglutition efficiency outcomes. However, the qualitative analysis showed that the preservation of both arytenoids and the absence of functional abnormalities were associated with more satisfactory voice and deglutition patterns.
\end{abstract}

received

August 8, 2017

accepted

December 17, 2017

published online

March 29, 2018
DOI https://doi.org/

10.1055/s-0038-1625980. ISSN 1809-9777.
Copyright $\odot 2018$ by Thieme Revinter

Publicações Ltda, Rio de Janeiro, Brazil
License terms

(이 (1) $\Theta \circledast$ 


\section{Introduction}

First described in 1974, subtotal supracricoid laryngectomy with cricohyoidoepiglottopexy (CHEP) or cricohyoidopexy (CHP) is an alternative treatment for malignant laryngeal tumors that offers good oncological control for resecting glottic and supraglottic tumors. ${ }^{1,2}$ The indication for this surgery is limited to laryngeal tumors in which the cricoid cartilage and at least one functional arytenoid unit can be preserved. $^{3-5}$

The literature reports moderate-to-extreme voice and deglutition abnormalities after supracricoid laryngectomy; however, the role of the remaining arytenoids in the rehabilitation of these patients is controversial. The presence of both arytenoids is associated with favorable outcomes according to some studies, while in other studies it does not represent a positive prognostic factor. ${ }^{6}$

Due to the lack of vocal folds, the laryngeal configuration after subtotal laryngectomy is modified, and the remaining structures associated with the overlying mucosa become the new source of sound. In the case of reconstruction with CHEP, sound is produced through the contact of the remaining arytenoid with the epiglottis. However, even when the vibration of these structures is optimized through speech therapy, the patients exhibit vocal strain, vocal fatigue, and breathiness. ${ }^{7}$

Regarding swallowing, dysphagia has been reported in most cases of supracricoid laryngectomy, particularly with liquids. However, through speech therapy, adjustments are possible with the resumption of exclusive oral feeding and decannulation. ${ }^{6,8,9}$ Some patients may exhibit silent aspiration of small amounts of food without significant repercussions to the lungs. ${ }^{9,10}$

The literature indicates controversy regarding the impact of arytenoidectomy; the need for further studies to explore in detail the issue of preserving one or two arytenoids has been emphasized. ${ }^{6,11}$ In addition, little is known about the functional conditions of the remaining arytenoid(s) in these cases.

Some studies have assessed speech intelligibility in this population of patients. ${ }^{12,13}$ However, no studies evaluating the pleasantness of the voice from the perspective of general listeners were found.

Furthermore, no studies have performed a broader acoustic analysis of these patients' voices, including the measurement of formant frequencies. Such measurements, especially of the third and fourth formants, may provide relevant data when the shortening of the vocal tract is considered. Such data, together with the auditory-perceptual characteristics of the voice, may increase the knowledge regarding the voice and deglutition after supracricoid laryngectomy, and help determine the treatment and therapeutic prognosis of speech therapy.

The aim of the present study was to assess voice and deglutition parameters as a function of the conservation or removal of arytenoids.

\section{Method}

This investigation was a comparative, observational, crosssectional study of a case series.
The research project was approved by the Research Ethics Committee of the institution (under no. 335472).

All patients undergoing supracricoid laryngectomy with reconstruction via CHP or CHEP in the hospital where the research was performed over a two-year period (from January 2013 to January 2015) were invited to participate in the study.

Inclusion criteria: patients who had resumed exclusive oral feeding for at least one month, with or without tracheostomy, regardless of the postoperative time, and who had undergone radiotherapy and/or chemotherapy treatment.

Exclusion criteria: patients undergoing radiotherapy and/ or chemotherapy at the time of the assessment, and those with neurological impairment or psychiatric disorders diagnosed and described in the medical records or with a cognitive or motor impact that limited the execution of simple commands, communication, and/or swallowing.

The following procedures were performed ( - Fig. $\mathbf{1}$ ).

1. Recording of a laryngeal image for the functional assessment of the arytenoid cartilage: laryngoscopy was performed with a Karl Storz (Tuttlingen, Germany) $70^{\circ}$ nasofibrolaryngoscope; a Toshiba (Minato, Tokyo, Japan) IK-M41A CCD micro-camera; a Sony (Minato, Tokyo, Japan) SLV-60HFBR VHS DVD media recorder; a Sony KV-1311 CR video monitor; and a ML-8 microphone (Le son, São Paulo, Brazil). The patients remained seated in a chair appropriate for an ear, nose, and throat examination, with the cervical region bent slightly forward. The nasofibrolaryngoscope was introduced through the wider nasal cavity without the use of topical anesthesia to avoid interference with pharyngeal and laryngeal sensitivity. The patients were instructed to breath in regularly, produce a sustained /é/ vowel, and then perform the pre-established tasks in the Brazilian Portuguese version of the consensus auditory-perceptual evaluation of voice (CAPE-V) protocol: ${ }^{14}$ the emission of vowels, sentences and spontaneous speech. The functional conditions of the arytenoid cartilage were consensually assessed by the physician and a speech therapist with extensive experience. This assessment was confirmed by both professionals after the end of the test based on digital image records.

The following parameters were considered for the classification of the conserved arytenoids: normal - the arytenoids exhibited no anatomical abnormalities and conserved their mobility and rotation; abnormal - edema, displacement and/ or overturning in each conserved arytenoid, regardless of an association with reduced mobility and/or fixation.

2. Videofluoroscopy (VF): performed with three types of food consistency - liquid, liquid-pasty and pasty. To standardize the test, no solid foods were used due to the large number of edentulous patients. This assessment was performed by a radiologist and a speech therapist. The examinations were performed with a Phillips (Amsterdam, Holland) DuoDiagnostic device that was field-collimated in the area of interest, with exposure parameters automatically set using an ionization chamber. To record swallowing, the patients were positioned standing for the anteroposterior and lateral-side views, staying as close as possible to the table top and the intensifier to avoid distortions of the fluoroscopic image. The contrast was 


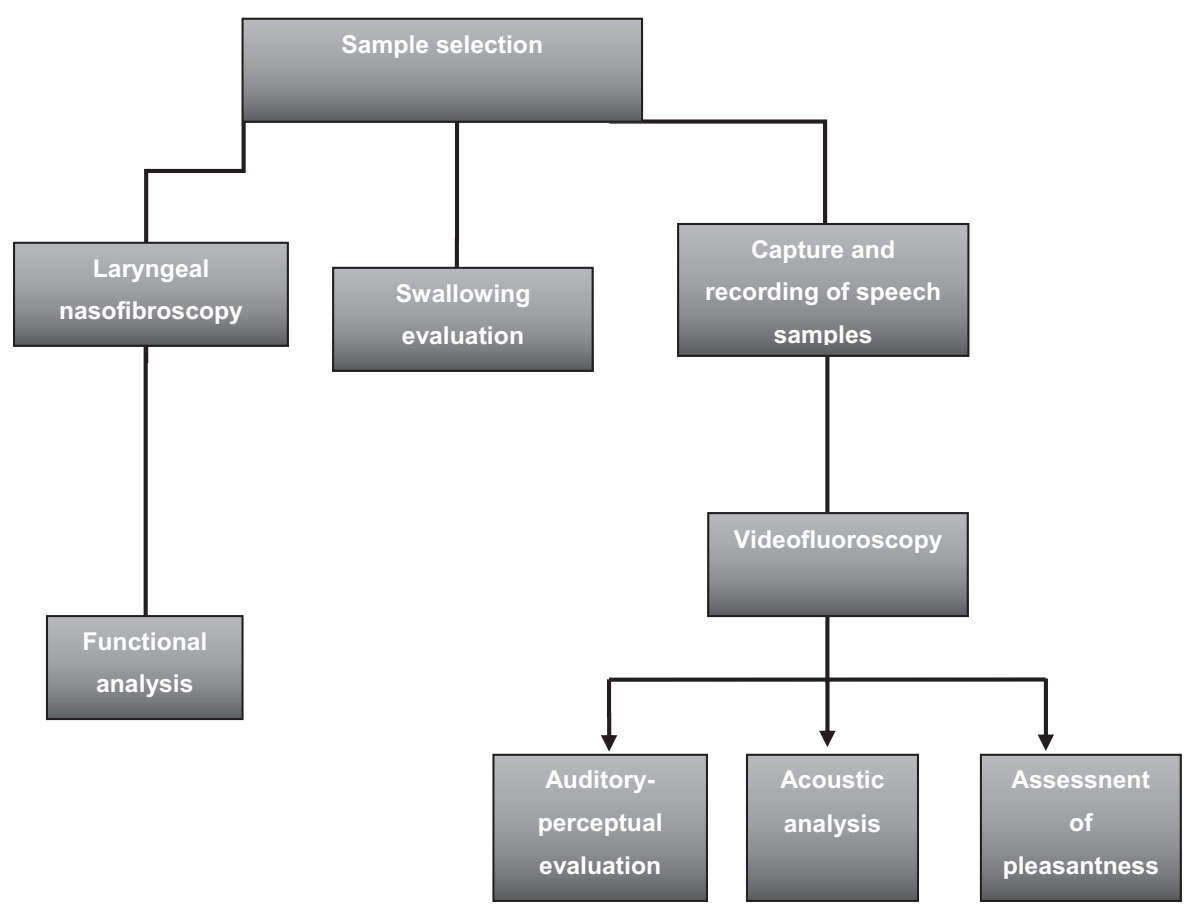

Fig. 1 Procedures performed in the study.

provided in a spoon using a $50 \%$ dilution of $100 \%$ barium sulfate (Bariogel, Cristália, Rio de Janeiro, RJ, Brazil) and 50\% food. For the preparation of the liquid-pasty consistency, $4.5 \mathrm{~g}$ of thickener were used in $100 \mathrm{ml}$ water, and for the pasty consistency, $9 \mathrm{~g}$ of thickener were used in $100 \mathrm{ml}$ water. For the liquid consistency, mineral water was used. The focus of the fluoroscopic image was bounded: in the anterior region by the lips; in the upper region by the nasal cavity; in the posterior region by the cervical spine; and in the lower region by the bifurcation of the airways and the cervical esophagus. The findings were subsequently analyzed by two speech therapists specializing in dysphagia and experienced with videofluoroscopy evaluation, and the results were obtained by consensus.

The VF was analyzed through a modification of the Logemann ${ }^{15}$ procedure, considering the presence or absence of the following parameters: penetration, silent penetration, aspiration, silent aspiration, and vallecular and/or hypopharyngeal stasis. Swallowing was analyzed after a single spontaneous deglutition or at most after the second, without the use of maneuvers for each food offered.

3. Recording of speech samples: voice samples were recorded with the participants performing again the tasks included in the Brazilian Portuguese version of the CAPE-V protocol. ${ }^{14} \mathrm{~A}$ desktop computer, the Audacity program, the Edirol UA-101 interface, and a unidirectional condenser AKG520 headset microphone (AKG, Vienna, Austria) were used. The microphone was positioned $3-5 \mathrm{~cm}$ from the patient's mouth, and at a $45^{\circ}$ to $90^{\circ}$ angles. During the vocal tasks, the individual sat comfortably with his back straight, and the evaluator was alert to any indication of stress resulting from the test.

4. Auditory-perceptual analysis of voice: the recorded voices were edited, assigned identification numbers, and organized in random order to ensure blinding. They were then presented to two raters who were speech therapists specializing in voice and experienced in the care of head and neck cancer patients. The raters analyzed the samples independently, without contact with each other. The speech samples were presented through speakers directly connected to the computer. The evaluations followed the CAPE-V protocol. ${ }^{14}$ Four voices from individuals with no complaints and no vocal changes were also analyzed; these cases composed the sample used to analyze intra-rater reliability.

5. Acoustic analysis: for this analysis, samples of at least three seconds of phonation of the sustained vowel /a/ were used. In the broadband analysis, the formants F3 and F4 were analyzed considering the mean of $2,500 \mathrm{~Hz}$ for $\mathrm{F} 3$ and $3,500 \mathrm{~Hz}$ for $\mathrm{F} 4 .^{16}$ In the narrowband analysis, the harmonics-to-noise ratio was extracted. The maximum phonation time was measured in milliseconds with a timer. The mean values for each item (formants F3 and F4, harmonics-to-noise ratio and maximum phonation time) were calculated.

6. Voice pleasantness using the visual analogue scale: voice pleasantness was analyzed by 22 undergraduate speech therapy students in the first year of the study program; the voice samples were presented in a silent room through speakers connected to the computer. The students could not talk to one another, and the voices were identified only by numbers. The analysis was performed quantitatively, and the classification was based on a $100-\mathrm{mm}$ visual analogue scale in which the extreme left represented a very pleasant voice, and the extreme right represented an extremely unpleasant voice. Subsequently, each distribution range was numerically and qualitatively tabulated; scores from $0 \mathrm{~mm}$ to $35.5 \mathrm{~mm}$ represented a pleasant voice; from $35.6 \mathrm{~mm}$ to $50.5 \mathrm{~mm}$, they represented 
a slightly pleasant voice; from $50.6 \mathrm{~mm}$ to $90.5 \mathrm{~mm}$, they represented an unpleasant voice; and from $90.6 \mathrm{~mm}$ to $100 \mathrm{~mm}$, the scores represented an extremely unpleasant voice (adapted from Yamasaki et al ${ }^{17}$ ). The mean pleasantness score of the voice was calculated.

\section{Analysis of the Results}

A descriptive analysis of the evaluated parameters was performed. Fisher test was used to compare the following variables: adjuvant therapy (radiotherapy and/or chemotherapy); and penetration, aspiration and stasis versus number (one or two) and functionality (normal or abnormal) of the remaining arytenoids. The significance level was set at $5 \%$. When the incidence was low, the distribution was described in absolute numbers.

The intra-rater reliability and inter-rater agreement were analyzed by calculating the Kappa coefficient.

\section{Results}

A total of 12 patients were selected during the study period. However, one patient did not undergo laryngeal nasofibroscopy due to disease recurrence, and was excluded at the end. The sample consisted of 11 men, all undergoing reconstruction with CHEP, and aged between 60 to 80 years old ( mean $=68.2$ years; standard deviation $=6.19$ years . Most of the patients had: tumors in stages T2 and T3; a 30-day interval from the surgery to the assessment; cervical lymph node dissection and the absence of a tracheostomy tube at the time of assessment; and moderate-to-severe dysphonia accompanied by roughness, breathiness, strain and loudness deviation (- Table $\mathbf{1}$ ).

Adjuvant treatment was prescribed to three patients, two due to positive $\mathrm{N}$ and one due to a positive margin.

The three patients who still had the tracheostomy tube in place at the time of the assessment exhibited postoperative complications (laryngeal stenosis), and two underwent an adjuvant treatment.

At the time of data collection, three patients had been discharged from speech therapy; the remaining patients were undergoing speech therapy to improve their voice patterns. All of the participants were consuming an oral diet, and were classified as levels 5 to 7 on the American Speech-Language Hearing Association National (ASHA) Outcome Measurement System (NOMS) Swallowing Rating Scale, ${ }^{18}$ which was considered safe deglutition for the purposes of the present study. The VF was performed one month after the reintroduction of the oral diet.

Eight patients had two preserved arytenoids; of these patients, six presented abnormal arytenoid functionality. Three patients had only one preserved arytenoid, and two of these patients exhibited some type of abnormality (-Table 2).

One patient exhibited epiglottic edema.

The VF detected silent penetration in the 5 patients with penetration (45.5\%); of these, 3 exhibited aspiration (27.3\%), which was silent in 1 case. Vallecular and hypopharyngeal stasis was detected in 4 cases (36.4\%).
Table 1 Sample characterization with case distribution according to tumor TNM stage, interval between surgery and assessment, adjuvant radiotherapy and/or chemotherapy, cervical lymph node dissection, tracheostomy at the time of the assessment and voice aspects in absolute numbers and percentages

\begin{tabular}{|c|c|}
\hline & N (\%) \\
\hline \multicolumn{2}{|l|}{ Stage } \\
\hline T1 & $3(27.2)$ \\
\hline $\mathrm{T} 2$ & $3(27.2)$ \\
\hline T3 & $5(45.5)$ \\
\hline No & $8(72.8)$ \\
\hline N1 & $3(27.2)$ \\
\hline M0 & $11(100)$ \\
\hline \multicolumn{2}{|c|}{ Interval between surgery and assessment } \\
\hline Up to 30 days & $7(63.6)$ \\
\hline Up to 60 days & $2(18.1)$ \\
\hline Up to 90 days & $2(18.1)$ \\
\hline \multicolumn{2}{|l|}{ Adjuvant therapy } \\
\hline Radio- and chemotherapy & $1(9.1)$ \\
\hline Radiotherapy & $3(27.3)$ \\
\hline \multicolumn{2}{|l|}{ Cervical lymph node dissection } \\
\hline Yes & $8(72.7)$ \\
\hline No & $3(27.2)$ \\
\hline \multicolumn{2}{|c|}{ Tracheostomy tube present at the time of the assessment } \\
\hline Yes & $3(27.2)$ \\
\hline No & $8(72.8)$ \\
\hline Total & $11(100)$ \\
\hline Voice aspects by CAPE-V & Mean \\
\hline Overall vocal deviation grade & 61.5 \\
\hline Roughness & 64.5 \\
\hline Breathiness & 66.5 \\
\hline Strain & 77.0 \\
\hline Pitch deviation & 55.0 \\
\hline Loudness deviation & 77.0 \\
\hline $\mathrm{F} 3(\mathrm{~Hz})$ & 3.124 \\
\hline $\mathrm{F} 4(\mathrm{~Hz})$ & 4.141 \\
\hline Harmonics-to-noise ratio (dB) & 2.6 \\
\hline
\end{tabular}

Abbreviations: CAPE-V, consensus auditory-perceptual evaluation of voice; TNM, tumor, nodes and metastasis.

Penetration was proportionally more frequent in the patients who underwent arytenoidectomy, and 2 of the 3 patients who had undergone the procedure exhibited aspiration. Among the cases in which both arytenoids were preserved, aspiration was observed in one case in which both arytenoids were functionally abnormal ( - Table 3 ).

The overall score for pleasantness of the voice was 71.3, which corresponds to an unpleasant voice. The mean number of sessions was 12.3. The patients with one preserved 
Table 2 Distribution of remaining arytenoid functionality in absolute numbers

\begin{tabular}{|l|l|l|l|l|l|l|}
\hline & $\begin{array}{l}\text { No } \\
\text { abnormality }\end{array}$ & Edema & Displacement & $\begin{array}{l}\text { Edema and } \\
\text { displacement }\end{array}$ & Total \\
\hline One arytenoid & 1 & & & 1 & 3 \\
\hline Preserved mobility with rotation & 1 & 1 & & & \\
\hline Fixed & \multicolumn{5}{|l|}{} \\
\hline Two arytenoids & 1 & 1 & & \\
\hline Preserved mobility with rotation & 2 & 1 & 1 & & \\
\hline One fixed & & & 2 & & 11 \\
\hline Both fixed & & & & & \\
\hline Total & & & & & \\
\hline
\end{tabular}

arytenoid exhibited a higher grade of voice deviation compared with the rest of the sample. The parameters maximum phonation time (MPT), voice pleasantness and number of sessions exhibited more favorable results when both arytenoids were preserved ( - Table 4 ).

A comparison considering the number of preserved arytenoids and arytenoid functionality showed that the mean values for vocal deviation and MPT were less satisfactory among the patients with functional abnormalities (- Table 5).

Similar results were obtained when the full sample was classified according to the functionality of the remaining arytenoids. The mean overall vocal deviation grade, MPT, pleasantness scale and number of sessions were more satisfactory in the patients without arytenoid functional abnormality (-Table 6).

Comparisons of the variables adjuvant therapy (radiotherapy and/or chemotherapy), penetration, aspiration and stasis versus number of preserved arytenoids (one or two) and functionality (normal or abnormal) of the preserved arytenoids indicated no significant difference $(p>0.05)$. The remaining variables could not be statistically compared due to their low incidence.

The intra-rater reliability and inter-rater agreement among the speech therapists and lay examiners were moderate.

\section{Discussion}

Because supracricoid laryngectomy has restricted indications, there are few reports of its outcomes in the literature, and the related case series are limited. Consequently, new studies that increase the knowledge regarding arytenoid preservation are valuable. Other aspects that justify the performance of new studies related to this surgical procedure are the heterogeneity of the assessments and the lack of guidelines indicating the risk and prognostic factors that are likely to optimize voice and deglutition outcomes. ${ }^{6,19}$

The sample consisted of male patients over 50 years old who had undergone supracricoid laryngectomy with reconstruction using CHEP, and the majority were classified as T2/ T3 in accordance with the case series reported in the

Table 3 Distribution of the sample regarding the number and functionality of the preserved arytenoid cartilages according to the presence of penetration, silent penetration, aspiration and silent aspiration on videofluoroscopy

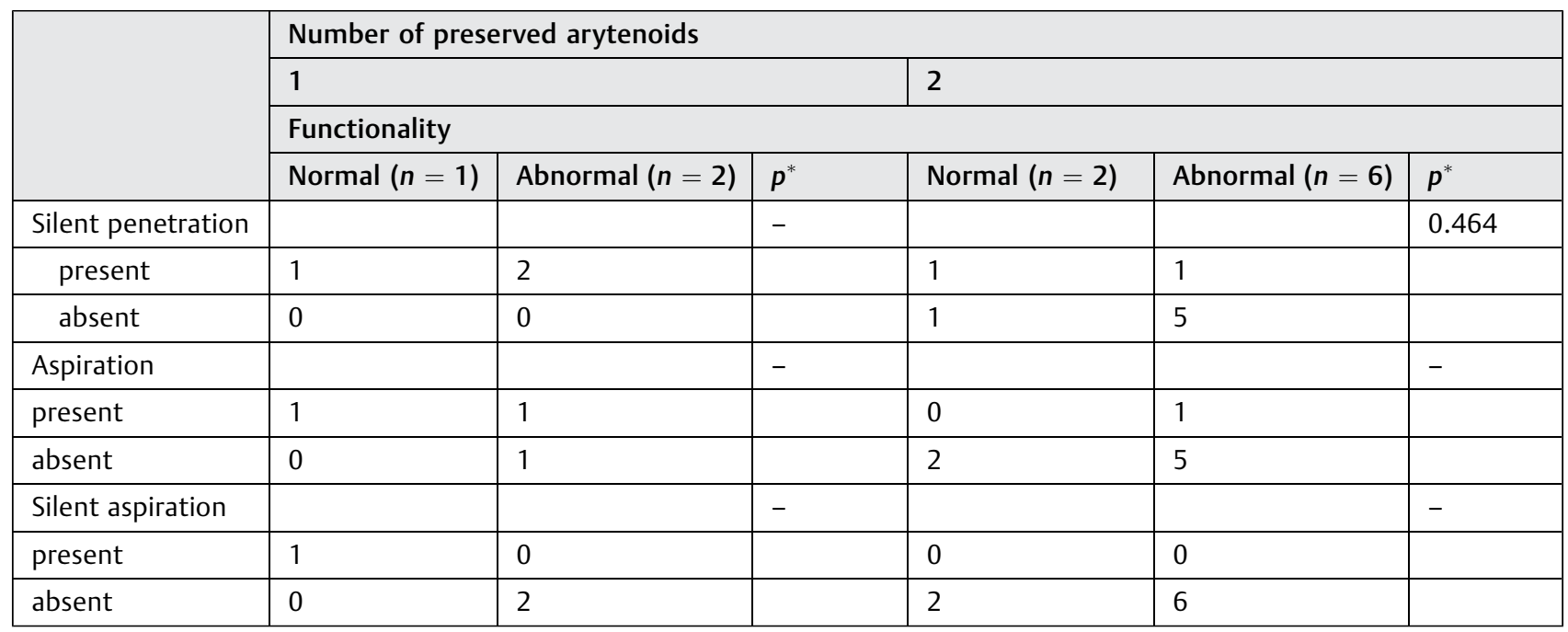

Note: *statistically significant, Fisher exact test. 
Table 4 Distribution of overall vocal deviation grade, maximum phonation time, pleasantness scale and number of sessions per number of preserved arytenoids

\begin{tabular}{|c|c|c|c|c|c|}
\hline & & \multicolumn{2}{|c|}{ Number of arytenoids } & \multirow{2}{*}{$\begin{array}{l}\text { Mean difference } \\
(95 \% \mathrm{Cl})\end{array}$} & \multirow[t]{2}{*}{$p^{*}$} \\
\hline & & 1 & 2 & & \\
\hline \multirow[t]{4}{*}{ Overall vocal deviation grade } & Mean & 82.17 & 53.75 & $28.5(7.7-49.1)$ & 0.064 \\
\hline & Median & 81.00 & 51.25 & & \\
\hline & $\begin{array}{l}\text { Standard } \\
\text { deviation }\end{array}$ & 7.816 & 22.533 & & \\
\hline & $\mathrm{N}$ & 3 & 8 & & \\
\hline \multirow[t]{4}{*}{ Maximum phonation time } & Mean & 4.133 & 5.113 & $-1.0(-3.6-1.6)$ & 0.608 \\
\hline & Median & 4.700 & 4.650 & & \\
\hline & $\begin{array}{l}\text { Standard } \\
\text { deviation }\end{array}$ & 1.3429 & 1.3314 & & \\
\hline & $\mathrm{N}$ & 3 & 8 & & \\
\hline \multirow[t]{4}{*}{ Pleasantness scale } & Mean & 77.67 & 68.88 & $8.8(-13.9-31.5)$ & 0.474 \\
\hline & Median & 84.00 & 73.50 & & \\
\hline & $\begin{array}{l}\text { Standard } \\
\text { deviation }\end{array}$ & 11.846 & 14.885 & & \\
\hline & $\mathrm{N}$ & 3 & 8 & & \\
\hline \multirow[t]{4}{*}{ Number of sessions } & Mean & 13.67 & 11.88 & $1.8(-6.0-9.6)$ & 0.537 \\
\hline & Median & 14.00 & 9.00 & & \\
\hline & $\begin{array}{l}\text { Standard } \\
\text { deviation }\end{array}$ & 3.512 & 7.661 & & \\
\hline & $\mathrm{N}$ & 3 & 8 & & \\
\hline
\end{tabular}

Abbreviation: 95\% Cl, 95\% confidence interval.

Note: *statistically significant, Wilcoxon test.

literature. ${ }^{3,5,6,11,20,21}$ Schindler et $\mathrm{al}^{6}$ published an extensive review of supracricoid laryngectomy procedures in which $28 \%$ of 25 articles had samples smaller than 20 cases. Many studies do not focus specifically on supracricoid laryngectomies, comparing them with other types of surgical procedures. $^{6,22,23}$

Adjuvant therapy was prescribed for patients with more advanced stages of the disease or positive margins. So et al ${ }^{12}$ reported indications for radiotherapy in 10 out of 15 patients who underwent supracricoid laryngectomy; there was no difference in the functional outcomes between the patients who underwent radiotherapy and those who did not. The use of radio- and chemotherapy was not associated with the number of preserved arytenoids or arytenoid functionality. There was no difference in the mean age between the patients who underwent adjuvant therapy and those who did not.

Other studies suggested an assessment of the laryngeal configuration using laryngoscopy and ensuring that the

Table 5 Sample distribution of the overall vocal grade deviation, maximum phonation time and pleasantness scale according to the number and functionality of the preserved arytenoid cartilages

\begin{tabular}{|c|c|c|c|c|c|c|c|c|}
\hline & \multicolumn{8}{|c|}{ Number of preserved arytenoids } \\
\hline & \multicolumn{4}{|l|}{1} & \multicolumn{4}{|l|}{2} \\
\hline & \multicolumn{8}{|c|}{ Functionality } \\
\hline & $\begin{array}{l}\text { Normal } \\
(n=1)\end{array}$ & $\begin{array}{l}\text { Abnormal } \\
(n=2)\end{array}$ & $\begin{array}{l}\text { Md } \\
(95 \% \mathrm{Cl})\end{array}$ & $p^{*}$ & $\begin{array}{l}\text { Normal } \\
(n=2)\end{array}$ & $\begin{array}{l}\text { Abnormal } \\
(n=6)\end{array}$ & $\begin{array}{l}\text { Md } \\
(95 \% \mathrm{Cl})\end{array}$ & $p^{*}$ \\
\hline $\begin{array}{l}\text { Overall vocal } \\
\text { deviation grade }\end{array}$ & 81 & 83 & -2.0 (n.a.) & - & 50.5 & 55 & -4.3 (n.a.) & 0.615 \\
\hline $\begin{array}{l}\text { Maximum } \\
\text { phonation time }\end{array}$ & 5.1 & 3.6 & 1.5 (n.a.) & - & 5.9 & 4.8 & $1.1(-7.0-9.3)$ & 0.311 \\
\hline Pleasantness scale & 64 & 84 & -20.5 (n.a.) & - & 71 & 68 & $3.5(-15.0-22.1)$ & 1.000 \\
\hline
\end{tabular}

Abbreviations: $95 \% \mathrm{Cl}$, $95 \%$ confidence interval; Md, Mean difference; n.a., not available.

Note: *statistically significant, Wilcoxon test. 
Table 6 Distribution of overall vocal deviation grade, maximum phonation time, pleasantness scale and number of sessions according to arytenoid function

\begin{tabular}{|c|c|c|c|c|c|}
\hline & & \multicolumn{4}{|c|}{ Arytenoid abnormality } \\
\hline & & No & Yes & Md $(95 \% \mathrm{Cl})$ & $p^{*}$ \\
\hline \multirow{4}{*}{$\begin{array}{l}\text { Overall vocal deviation } \\
\text { grade }\end{array}$} & Mean & 60.67 & 61.81 & $-1.1(-63.3-61.1)$ & 1.000 \\
\hline & Median & 75.00 & 66.50 & & \\
\hline & $\begin{array}{l}\text { Standard } \\
\text { deviation }\end{array}$ & 30.172 & 22.723 & & \\
\hline & $\mathrm{N}$ & 3 & 8 & & \\
\hline \multirow{4}{*}{$\begin{array}{l}\text { Maximum phonation } \\
\text { time }\end{array}$} & Mean & 5.667 & 4.538 & $1.2(-1.3-3.6)$ & 0.151 \\
\hline & Median & 5.100 & 4.500 & & \\
\hline & $\begin{array}{l}\text { Standard } \\
\text { deviation }\end{array}$ & 1.2503 & 1.3201 & & \\
\hline & $\mathrm{N}$ & 3 & 8 & & \\
\hline \multirow[t]{4}{*}{ Pleasantness scale } & Mean & 69.00 & 72.13 & $-3.1(-17.9-11.7)$ & 0.413 \\
\hline & Median & 69.00 & 77.00 & & \\
\hline & $\begin{array}{l}\text { Standard } \\
\text { deviation }\end{array}$ & 5.000 & 16.600 & & \\
\hline & $\mathrm{N}$ & 3 & 8 & & \\
\hline \multirow[t]{4}{*}{ Number of sessions } & Mean & 13.33 & 12.00 & $1.3(-10.9-13.6)$ & 0.837 \\
\hline & Median & 17.00 & 9.50 & & \\
\hline & $\begin{array}{l}\text { Standard } \\
\text { deviation }\end{array}$ & 6.351 & 7.151 & & \\
\hline & $\mathrm{N}$ & 3 & 8 & & \\
\hline
\end{tabular}

Abbreviation: 95\%Cl, 95\% confidence interval; Md, Mean difference.

Note: *statistically significant, Wilcoxon test.

analysis was performed by professionals with extensive experience. ${ }^{12,13,24,25}$

Regarding the characteristics of the neoglottis and its interference with voice production and deglutition functions, the literature has shown an association between these functions and the type of reconstruction; furthermore, published studies have analyzed the effects of the presence of one or two arytenoids on supracricoid laryngectomy outcomes. In a previous study, Nemr et $\mathrm{al}^{11}$ observed 22 cases ( 7 CHP and 15 CHEP) and found that the glottis was the primary site associated with moderate dysphagia, and that the supraglottis was primarily associated with severe dysphagia. The progression of dysphagia was better than that of dysphonia; in addition, the degree of dysphagia and dysphonia was not associated with the presence of one or two arytenoids. Park et $\mathrm{al}^{26}$ compared 84 patients with 2 preserved arytenoids with 32 patients who had 1 preserved arytenoid, and observed a better functional outcome in those without arytenoidectomy. Schindler et $\mathrm{al}^{6}$ called attention to the fact that this parameter is still controversial in the literature, which reinforces the need for further studies on this subject.

In the present study, the presence of one versus two arytenoids was not a determinant of deglutition performance in the assessed individuals. However, a case-by-case analysis showed penetration and aspiration in the three patients with one preserved arytenoid, including the one patient whose remaining arytenoid was functionally normal. Another relevant finding is that the cartilages were abnormal in six of the eight patients with two preserved arytenoids. The two cases without arytenoid functional abnormality exhibited silent penetration, and one of them also exhibited stasis. It should be noted that all of the participants had undergone speech therapy and were in a safe deglutition condition. ${ }^{18}$ Videofluoroscopy enables the visualization of the aspiration of small amounts of food, which are often not identifiable on clinical assessments or with video endoscopy. Some studies have suggested the routine performance of VF to assess deglutition in this population of patients, regardless of whether they have undergone arytenoidectomy or not. ${ }^{9,20}$ In the present study, VF was performed one month after the oral diet was reintroduced, a time interval considered adequate for the instrumental assessment of deglutition conditions.

Zacharek et al, ${ }^{27}$ in a study with 10 cases of supracricoid laryngectomy (4 CHP and 6 CHEP), highlighted the fact that the 3 patients who had undergone VF exhibited significant aspiration; however, they did not develop postoperative pneumonia, and they made satisfactory progress with the reintroduction of an oral diet. These authors described data suggesting the importance of the mobility of the arytenoid cartilages, the action of the base of the tongue, and the 
remaining supraglottic tissue for a competent neoglottic sphincter with consequent vibration during phonation, and airway protection during swallowing.

This detailing of the functional conditions of the preserved arytenoids can help clinicians understand prognostic factors and determine the therapeutic techniques that will hasten the reintroduction of an oral diet and promote an improvement in the final vocal quality.

There is a consensus in the literature that the voice is the most severely impaired function after supracricoid laryngectomy. ${ }^{6}$ This fact led specialists to seek alternatives to minimize the negative impact on communication. Allegra et $\mathrm{al}^{13}$ detected a better voice pattern in a group of patients that underwent modified supracricoid laryngectomy involving the use of the sternohyoid muscle compared with a group treated using the conventional technique.

In the auditory-perceptual analysis of voice, strain and loudness deviation were considered severe, which corroborates the reports in the literature that patients who underwent subtotal laryngectomy maintain marked dysphonia., 11,23 Relative to the overall vocal deviation grade, the qualitative analysis showed that dysphonia was moderate among the participants who had not undergone arytenoidectomy, and that it was severe among those with a single preserved arytenoid. The difference in the overall voice deviation grade according to the functionality of the remaining arytenoid, in absolute numbers, was practically the same.

Another notable issue related to the auditory-perceptual analysis of voice is that most of the reviewed articles used the grade, roughness, breathiness, asthenia, and strain (GRBAS) scale. ${ }^{3,22,23,28,29}$ In patients with severe voice changes resulting from the surgical procedure discussed here, the CAPE-V is considered the most adequate instrument for this type of analysis because, in addition to considering all the aspects included in the GRBAS scale, it comprises the perception of pitch and loudness (which exhibited severe abnormalities in the investigated sample). In addition, the CAPE-V with $100-$ $\mathrm{mm}$ visual analogue scale enables a much more detailed assessment of vocal deviation; for instance, it can establish whether a moderate degree of dysphonia is closer to the mild or the severe degrees. Furthermore, it enables better monitoring of therapy progression with the perception of discreet improvements. $^{30}$

The mean maximum phonation time remained below normal limits due to inefficient glottal closure; the mean value found was similar to that reported in a previous study. ${ }^{12}$ Higher mean values were obtained in a study that assessed 24 patients with a mean interval of 34.5 months between the surgery and the assessment. ${ }^{3}$ As most participants in the present study were still undergoing speech therapy at the time of data collection, and considering that the interval from the surgery to the assessment was pf up to 3 months, a course of speech therapy longer than the average undergone by the present study's sample (12.3 sessions) might help to improve some voice parameters, especially MPT. It should be noted that in absolute terms, the MPT was longer among the individuals with two preserved arytenoids. The same was true for the group with functionally normal arytenoids.
In addition, the possible coexistence of chronic lung diseases in these patients with respiratory limitations cannot be dismissed. The presence of lung disease may contribute to a reduced MPT, in addition to the limitations expected from age and neoglottic space. Therefore, the results of aerodynamic measures may contribute to a greater understanding of the phonation mechanism of these individuals and the limits of speech therapy. These factors further corroborate the loudness deviations found in the analyzed sample.

Regarding the short-term acoustic analysis, the narrow band filter provides relevant data regarding the presence and amount of harmonics and the harmonics-to-noise ratio. The mean harmonics-to-noise ratios were below the reference value due to the lower degree of glottal closure, which favors vocal production with fewer harmonics and more noise. This finding is in agreement with the literature. ${ }^{3,31}$

The broadband filter enabled an analysis of the formants. The third formant (F3) is influenced by cavities formed behind and in front of the constriction of the tongue, and the fourth formant (F4) is influenced in part by the length of the vocal tract and in part by the dimensions of the laryngeal tube and the surrounding area. Considering that the frequency of the formants is influenced by the length of the vocal tract (the longer the vocal tract, the lower the frequencies of the formants), ${ }^{16}$ we chose to investigate $\mathrm{F} 3$ and $\mathrm{F} 4$ as a function of the shortening of the vocal tract and the neoglottis.

The F3 and F4 means were above the reference values, confirming the hypothesis that the length of the vocal tract and the neoglottis influence the formant frequencies. The reference values used in this study were extracted from the Swedish language, as reference values for Brazilian Portuguese corresponding to the study's population of elderly men were not found. Even when the mean F3 for young men in Brazilian Portuguese $(2,638 \mathrm{~Hz} \text {, with a standard deviation of } 120 \mathrm{~Hz})^{32}$ was considered, the values exceeded this mean. Considering that the elderly larynx is lower and thus all formants are lower in frequency compared with young adults, the values obtained in this study support the elevation of the neolarynx and pharynx constriction as a function of the neoglottis.

No studies that measured formants in partial or subtotal laryngectomy patients were found. This measurement may be relevant for the comparative assessment of individuals without voice abnormalities, and to monitor the progression of the treatment.

Formant measurement has been scarcely addressed in studies on head and neck cancer. Timon et $\mathrm{al}^{33}$ investigated the impact of thyroidectomy on the vocal tract based on F1 and F2, and suggested that the patients who underwent thyroid surgery presented a significant reduction in vocal tract stability compared with the controls. They further noted that the aforementioned measurements offer a potential instrument to investigate the functional implications of any thyroid surgeryrelated disturbance of pharyngeal innervations.

The association among the limitations of vibrational structures in the neoglottic source, possible functional changes in the remaining arytenoids, and the changes resulting from the shortening of the vocal tract as a result of laryngeal elevation may explain the unsatisfactory final 
vocal pattern resulting from supracricoid laryngectomy and, consequently, the young adults' perceptions of these patients' voices as unpleasant.

Naudo et $\mathrm{al}^{10}$ evaluated phonation as good or satisfactory in $97 \%$ of supracricoid laryngectomy patients at the 12 th postoperative month. Dworkin et $\mathrm{al}^{24}$ performed an auditory-perceptual evaluation of the voice in 10 individuals undergoing supracricoid laryngectomy, and found a mean of 2.8 on a 5-point scale in which 1 represented poor vocal quality, and 5 , excellent vocal quality. The authors called attention to the differences between CHP and CHEP, mentioning that preservation of the epiglottis can facilitate the rehabilitation process by providing a stable opposing anatomical surface against which the mobile arytenoid(s) can establish neoglottic closure. Notably, none of these studies included assessments performed by inexperienced examiners; in contrast, the present study included firstyear speech therapy undergraduate students as examiners. In the analyzed sample, both the overall mean voice pleasantness and the numerical differences between the groups according to the number of arytenoids and arytenoid functionality were within the range rated as unpleasant. It should be noted that most of the participants were still undergoing speech therapy to improve their vocal pattern.

This finding suggests the need to reflect upon how the general public might perceive these voices, a factor that can negatively affect the patients' quality of life, especially during conversations with strangers, on the phone, or in noisy environments.

The students' perceptions of the patients' voices as unpleasant plus the functional conditions presented in this study reinforce the need to deepen the knowledge regarding supracricoid laryngectomy.

The findings of the present analysis shed light on two aspects that require more thorough study. Firstly, the therapeutic tests to select the vocal techniques that are most likely to optimize the vocal pattern within the shortest possible course of speech therapy should be studied; and secondly, ongoing research regarding the impact of the number and functionality of the remaining arytenoids should be performed with larger samples to establish prognostic factors for satisfactory voice and deglutition.

Some limitations of the present study should be noted. The small sample size may account for the lack of statistical evidence related to the number and functionality of the remaining arytenoids. Multicenter studies might provide more robust results, and, consequently, guide the formulation of new paradigms for voice and deglutition after supracricoid laryngectomy.

Three patients who still had the tracheostomy tube in place at the time of the assessment exhibited postoperative complications, and two underwent adjuvant treatment. The presence of these patients in the studied sample should be considered a potent confounding factor, since the data of their evaluations could be more altered, which is not clear when observing the data individually, and, due to the small sample size, it cannot be further analyzed.
One of the contributions of this study is that it alerts specialists to the need to pay attention to the condition of the remaining arytenoids and to the auditory-perceptual and acoustic aspects of the voice, including acoustic measurements of formant frequency. A multi-professional assessment at the onset of speech therapy that considers the aspects emphasized in the present study will help specialists formulate strategies to obtain more favorable outcomes in terms of voice quality, with consequent improvement of the patients' quality of life. Similarly, it is necessary to manage deglutition using VF following the clinical assessment of safe deglutition.

\section{Conclusion}

In the present sample of elderly men who underwent CHEP, both arytenoids were preserved and exhibited functional abnormalities in most cases. Videofluoroscopy performed one month after the reintroduction of an exclusive oral diet enabled the management of dysphagia, which proved to be persistent in a large portion of the analyzed sample that exhibited silent penetration, aspiration of small amounts of food, and/or vallecular and hypopharyngeal stases.

The participants exhibited moderate-to-severe dysphonia accompanied by roughness, breathiness, strain, and loudness deviation. The maximum phonation time and harmonics-tonoise ratio were below the reference range, while the mean value of the third and fourth formants were above the reference range. The participants' voices were rated as unpleasant by young adults.

The number and functionality of the preserved arytenoids were not found to be prognostic factors for favorable deglutition efficiency outcomes. However, the qualitative analysis showed that the preservation of both arytenoids and the absence of functional abnormalities were associated with more satisfactory voice and deglutition patterns.

\section{References}

1 Piquet JJ, Desaulty A, Decroix G. Crico-hyoido-epiglotto-pexy. Surgical technic and functional results. Ann Otolaryngol Chir Cervicofac 1974;91(12):681-686

2 Pressman JJ. Submucosal compartmentation of the larynx. Ann Otol Rhinol Laryngol 1956;65(03):766-771

3 Saito K, Araki K, Ogawa K, Shiotani A. Laryngeal function after supracricoid laryngectomy. Otolaryngol Head Neck Surg 2009; 140(04):487-492

4 Gonçalves AJ, Bertelli AA, Malavasi TR, Kikuchi W, Rodrigues AN, Menezes MB. Results after supracricoid horizontal partial laryngectomy. Auris Nasus Larynx 2010;37(01):84-88

5 Nakayama M, Miyamoto S, Seino Y, Okamoto T, Kano K. Neoglottal revisions after supracricoid laryngectomy with cricohyoidoepiglottopexy. Jpn J Clin Oncol 2016;46(07):642-645

6 Schindler A, Pizzorni N, Mozzanica F, et al. Functional outcomes after supracricoid laryngectomy: what do we not know and what do we need to know? Eur Arch Otorhinolaryngol 2016;273(11): 3459-3475

7 Fouquet ML, Vieira TPG, Murata CJM, Gonçalves AJ. Efeito imediato da técnica de firmeza glótica nas laringectomias parciais horizontais supracricoides: estudo inicial. Rev Soc Bras Fonoaudiol 2012;17(03):346-350 
8 Kruk-Zagajewska A, Szmeja Z, Szyfter W, Wójtowicz J, Citowicki W, Wierzbicka M. [Swallowing disorders in patients after the laryngeal cancer surgery]. Otolaryngol Pol 1995;49(01):15-22

9 Lewin JS, Hutcheson KA, Barringer DA, et al. Functional analysis of swallowing outcomes after supracricoid partial laryngectomy. Head Neck 2008;30(05):559-566

10 Naudo P, Laccourreye O, Weinstein G, Jouffre V, Laccourreye H, Brasnu D. Complications and functional outcome after supracricoid partial laryngectomy with cricohyoidoepiglottopexy. Otolaryngol Head Neck Surg 1998;118(01):124-129

11 Nemr NK, Carvalho MB, Kohle J, Leite GCAL, Rapoport A, Szeliga RMS. Estudo funcional da voz e da deglutição na laringectomia supracricóide. Rev Bras Otorrinolaringol 2007;73(02):151-155

12 So YK, Yun YS, Baek CH, Jeong HS, Son YI. Speech outcome of supracricoid partial laryngectomy: comparison with total laryngectomy and anatomic considerations. Otolaryngol Head Neck Surg 2009;141(06):770-775

13 Allegra E, Lombardo N, La Boria A, et al. Quality of voice evaluation in patients treated by supracricoid laryngectomy and modified supracricoid laryngectomy. Otolaryngol Head Neck Surg 2011; 145(05):789-795

14 Behlau M. Consensus Auditory- Perceptual Evaluation of Voice (CAPE-V), ASHA 2004. Refletindo sobre o novo/New reflexions. Rev Soc Bras Fonoaudiol 2004;9(03):187-189

15 Logemann JA. Evaluation and treatment of swallowing disorders. 2nd ed. Texas: Pro ED; 1998

16 Sundberg J. Ciência da voz: fatos sobre a voz na fala e no canto. Trad. Salomão GL. São Paulo: Editora da Universidade de São Paulo; 2015

17 Yamasaki R, Madazio G, Leão SHS, Padovani M, Azevedo R, Behlau M. Auditory-perceptual evaluation of normal and dysphonic voices using the voice deviation scale. J Voice 2017;31 (01):67-71

18 American Speech-Language Hearing Association National Outcome Measurement System (NOMS). Adults speech-language pathology training manual. Rockville, Md: American SpeechLanguage Hearing Association; 1998

19 Marioni G, Marchese-Ragona R, Ottaviano G, Staffieri A. Supracricoid laryngectomy: is it time to define guidelines to evaluate functional results? a review. Am J Otolaryngol 2004;25(02): 98-104

20 Prado PRP, Dias FL, Santos IC, Freitas E, Ferreira LP. Avaliação videofluoroscópica no pós-operatório tardio de pacientes sub- metidos à laringectomia supracricoidea com cricohioidoepiglotopexia. Rev Bras Cir Cabeça Pescoço 2012;41(03):124-127

21 Ozturk K, Akyildiz S, Gode S, et al. Post-surgical and oncologic outcomes of supracricoid partial laryngectomy: a single-institution report of ninety cases. ORL J Otorhinolaryngol Relat Spec 2016;78(02):86-93

22 Torrejano G, Guimarães I. Voice quality after supracricoid laryngectomy and total laryngectomy with insertion of voice prosthesis. J Voice 2009;23(02):240-246

23 Crosetti E, Garofalo P, Bosio C, et al. How the operated larynx ages. Acta Otorhinolaryngol Ital 2014;34(01):19-28

24 Dworkin JP, Meleca RJ, Zacharek MA, et al. Voice and deglutition functions after the supracricoid and total laryngectomy procedures for advanced stage laryngeal carcinoma. Otolaryngol Head Neck Surg 2003;129(04):311-320

25 Makeieff M, Giovanni A, Guerrier B. Laryngostroboscopic evaluation after supracricoid partial laryngectomy. J Voice 2007;21(04): 508-515

26 Park JO, Joo YH, Cho KJ, Kim NG, Kim MS. Functional and oncologic results of extended supracricoid partial laryngectomy. Arch Otolaryngol Head Neck Surg 2011;137(11):1124-1129

27 Zacharek MA, Pasha R, Meleca RJ, et al. Functional outcomes after supracricoid laryngectomy. Laryngoscope 2001;111(09):1558-1564

28 Schindler A, Favero E, Nudo S, Albera R, Schindler O, Cavalot AL. Long-term voice and swallowing modifications after supracricoid laryngectomy: objective, subjective, and self-assessment data. Am J Otolaryngol 2006;27(06):378-383

29 Bron L, Pasche P, Brossard E, Monnier P, Schweizer V. Functional analysis after supracricoid partial laryngectomy with cricohyoidoepiglottopexy. Laryngoscope 2002;112(7 Pt 1):1289-1293

30 Nemr K, Simões-Zenari M, Cordeiro GF, et al. GRBAS and Cape-V scales: high reliability and consensus when applied at different times. J Voice 2012;26(06):812.e17-812.e22

31 Portas JG, Queija DdosS, Arine LP, et al. Voice and swallowing disorders: functional results and quality of life following supracricoid laryngectomy with cricohyoidoepiglottopexy. Ear Nose Throat J 2009;88(10):E23-E30

32 Svicero MAF. Caracterização acústica e de imagens de ultrassonografia das vogais orais do Português Brasileiro [dissertação]. São Paulo: Pontifícia Universidade Católica de São Paulo; 2012

33 Timon CI, Hirani SP, Epstein R, Rafferty MA. Investigation of the impact of thyroid surgery on vocal tract steadiness. J Voice 2010; 24(05):610-613 